\title{
Família, escola, comunidade/sociedade: Contiguidades educativas
}

\section{Family, school, community/society: Educatives contiguousness}

\author{
Isaura Dores Gomes Sousa, Maria de Fátima Rodrigues da Torre, Maria Amélia Machado Rua, Carla Marina Alves \\ Lopes Alexandre \\ Casa do Professor de Chaves
}

\begin{abstract}
Resumo
Um dos problemas mais sérios que a formação cidadã enfrenta, hoje, é a que chamamos de "déficit de socialização" que se manifestam o caráter da sociedade atual. Por essa razão, a nossa primeira preocupação é mostrar a imagem da necessidade de harmonizar os quatro grandes fundamentos educativos para se ser responsável por colocar em prática o seu próprio campo de atividade missionária, ter em conta a contiguidade gradual entre si. Desta forma, no nosso trabalho, desenvolvemos o nosso objetivo neste molde: (1) Família - a estrutura da personalidade, identidade, unicidade; (2) Escola educação / ensino-aprendizagem; (3) - Comunidade - para usar o conhecimento útil (4) Sociedade - para se oferecer os meios necessários para responder neste mundo cada vez mais global.

Palavras-chave: Família, escola, comunidade, sociedade
\end{abstract}

Abstract

One of the Problems more serious that the formation of the citizen affront, today, is to that we be call «deficit of socialización» who manifest one's character of the society atual. For that reason, our first preoccupation is show image of the needfulness imperative to harmonize the four great educatives ground for to be answerable to put in gear her own field of missionary activity, to have in count the gradual contiguity between themself. In this way, our work we develop our's maind in this mould: (1) Family the structure of the personality, identity, oneness; (2) School - educacion / teaching-apprentisechip; (3) Community - to aplay useful knowledge (4) Society - to offer oneself the ways and means necessary to answer in this world more and more global.

Keywords: Family, school, community, society

\section{"A criança identifica-se com os outros} significantes

numa variedade de formas emocionais; mas sejam elas quais forem,

a sua interiorização produz-se só quando se produz a identificação".

(P. Berger y Th. Luckman, (1968), citado por J. C. Tedesco, (1995:38).

\section{Introdução}

A temática apresenta-se-nos, na verdade, deveras interessante. É aí que tudo começa.
Mas, será aí que tudo termina?

Ser criança, requer, desde o primeiro momento, uma consciencialização deveras ponderada, querida e assumida pelos seus progenitores, pai e mãe, num ambiente onde o amor seja a fonte geradora de oportunidades adequadas ao seu desenvolvimento saudável, de corpo e de alma. Independentemente do tipo de família que caracteriza a sociedade dos nossos dias, requerem-se parcerias cujas finalidades se entrosem em verdadeiras COMUNIDADES EDUCATIVAS.

É nesta "Pós-Modernidade", com todos os seus avanços e recuos, condicionalismos e consequências, teorias, tantas vezes, desfasadas das práticas, que, as nossas crianças, os nossos adolescentes, os nossos jovens, os nossos adultos enquadrados nos vários escalões etários, temos que nos mover, através de acções concretas, devidamente ajustadas aos vários contextos, sociais, culturais geo-mundiais que, tantas vezes, ultrapassam as nossas expectativas mais íntimas, naturais, humanas. Mover-nos, neste mundo mais máquina que humano.

Agir em conformidade exige de cada ser humano um conhecimento profundo que se vai adquirindo, estruturando, enraizando de acordo com as potencialidades que se nos oferecem e que, em contrapartida, requeremos.

Eis a questão que se constitui como razão de ser de qualquer PSICOPEDAGOGO que se envolve na missão mais significativa da vida humana. Missão que se vai traduzindo em actos revertidos naquilo que somos: naquilo que "TU ÉS", naquilo que "EU SOU", naquilo que "NÓS SOMOS" como "PESSOA E PESSOA IMPORTANTE".

Grande a responsabilidade que recai sobre cada um/a de nós, Educadores deste Século XXI, o século que se propôs conquistar para dominar os ares, ainda que descurando o mundo global que herdámos. A Era das Tecnologias veio para ficar e para ultrapassar todas as aprendizagens que, à partida, julgávamos seguras.

A complexidade de saberes projecta-nos na complexidade de fazeres que nos são atribuídos pelas forças das circunstâncias em que todo o nosso trabalho se desenvolve. A sua complexidade tem que ser desmistificada por cada agente/actor educativo para o 
adaptar ao local incluído no âmbito de um global de que não podemos alhear-nos.

Agir será pois a palavra de ordem para o sucesso.

\section{Em Famíla ... Ser Pessoa}

Numa definição, algo simplista, quanto habitual, podemos referir que uma PESSOA é qualquer INDIVÍDUO/A com quem convivemos, com quem nos cruzamos, ao longo da VIDA.

Nos dias de hoje, Ser Pessoa ... em Família, traz consigo um sentido multiplural tão vasto e complexo que qualquer PSICOPEDAGOGO tem que conhecer para aplicar, adaptando, esse conhecimento de acordo com as situações vivenciadas por cada um/a dos/as seus/suas educandos/as.

Sendo a família o primeiro agente de socialização da criança, pensamos nela como o lugar onde nascemos, crescemos e morremos, ainda que, no decorrer deste percurso, possamos ter mais do que uma família.

Temos consciência que é no espaço familiar onde se desenvolvem as aprendizagens mais significativas, quer no campo das interacções, como das vivências. Segundo Alarcão (2000), na dimensão das interacções privilegia-se "os contactos corporais, a linguagem, a comunicação, as relações interpessoais”, enquanto na dimensão das vivências subsistem "relações afectivas profundas: a filiação, a fraternidade, o amor, a sexualidade... numa trama de emoções e afectos positivos e negativos que, na sua elaboração, vão dando corpo ao sentimento de sermos quem somos e de pertencermos àquela e não a outra família".

SER PESSOA, nesta actualidade pluridimensional, tem que ultrapassar as ideias simplistas com que, não raras vezes, somos confrontados. Temos que ir mais longe, aprofundando o sentido que as próprias palavras encerram, em si mesmas. E, se o fizermos, o nosso comportamento, decerto, se adequará a cada situação circunstancial, seja no campo individual mais restrito, seja no campo colectivo, abrangendo o familiar, o comunitário, o social local. É aqui e agora que a nossa acção vai gerando frutos que tornam o social mais aprazível.

Conhecer a FAMÍLIA, peça fundamental de uma COMUNIDADE mais próxima, parte integrante de uma SOCIEDADE a que pertencemos, hoje mais que ontem, eis o papel fundamental que todo o Educador tem que assumir.

Para que o desenvolvimento se processe de forma coerente, articulada, equilibrada, de forma verdadeiramente consentânea com os valores que propugnamos, as relações pessoais que se estabelecem entre os vários campos educativos hão-de corresponder a uma razão dialógica entre os vários intervenientes no processo, os vários significantes propiciadores à interiorização adequada das aprendizagens que se vão adquirindo, produtoras da identificação que, cada ser, em crescimento, tem que assumir, assumindo-se.

É sob a influência da FAMÍLIA que se vão criando hábitos de higiene corporal e mental, se vão processando regras de conduta geradoras de bem estar e de bem ser, se vão adquirindo conhecimentos e práticas geradoras de mudança. Todo o processo de individualização e socialização encontram aí o húmus que lhes há-de alimentar vontades e, ao mesmo tempo, abrir caminhos frutificantes e fortificantes, altamente compensatórios.

É, aí, nessa estrutura familiar que se inicia o desenrolar do fio condutor a uma FORMAÇÃO DE QUALIDADE.

\section{Escola de ontem e de hoje}

Nessa da ESCOLA DE ONTEM E DE HOJE se inscreve toda a acção de um especialista devidamente creditado para dar continuidade a esse saber de que cada educando é portador, à chegada. Esse ser, tanto ACTOR, quanto AGENTE de cidadania a quem foi, é confiada.

Eis a premissa que nos propomos analisar, nos curtos minutos que nos são dedicados; eis a razão da aderência à proposta que assumimos e que colocamos à discussão, a fim de que cada qual, esse TU e este EU, a interprete $\mathrm{e}$ a interpenetre à sua própria medida e de acordo com o contexto que sustenta a nossa identidade vital, inscrita na nossa unidade nacional.

Segundo Juan Carlos Tedesco (1995:33), podemos considerar que já ninguém sabe, exactamente, onde esse contexto se situa. A IDENTIDADE do MOVIMENTO e do PENSAMENTO EDUCATIVO progressista está em crise. As respostas do PASSADO, por mais recente que o possamos considerar, já não são suficientes para definir a resposta político-educativa capaz de definir, muito menos de responder aos objectivos da democracia e equidade na aquisição distributiva do conhecimento.

O trabalho que apresentamos move-se entre um PASSADO que honramos, mas assenta, essencialmente, na conjugação entre este PRESENTE, já FUTURO, mas que é nosso, "teu e meu", neste "Nós" e neste AGORA que nos pertence.

Daí as CONTIGUIDADES que nos propusemos questionar, tão só, para advertir para a necessidade de REFLEXÃO/ACÇÃO relativamente ao PAPEL DA ESCOLA neste novo cenário social carregado de incertezas, de dúvidas, mas também, de esperanças, de convicções de que somos capazes.

É nessa acção reflexiva que encontramos a razão de ser PSICO-PEDAGOGO. Desmembrando a palavra conseguiremos atingir o seu significado mais profundo: Psico "alma / espírito"; Pedagogo/a cuja missão se traduz em "conduzir a criança", aquele/a que "orienta a conduta do OUTRO". Esse OUTRO/A que começa em TI e termina em MIM, e/ou, vice-versa, numa acção que nos envolve, contígua e permanentemente, que tem que ser devidamente aceite, assumida, partilhada, independentemente da origem Social de cada ser uno e indivisível.

Nesta reflexão estão presentes todas as experiências que, ao longo dos tempos, se tornaram o alvo primordial das nossas condutas, o cerne da nossa maneira de SER e de ESTAR, na Escola como na Vida, num quotidiano que relevamos como educadores/as, verdadeiramente, conscientes das nossas convicções em crescimento recíproco de ensino e aprendizagem.

Com Suarez Pazos (2002:107) aprendemos que

"No campo educativo, o mesmo sucede em outros

âmbitos sociais, o particular, pessoal e quotidiano 
foi silenciado em grande parte das investigações. Não obstante, nas últimas décadas cobra importância o mundo académico, o subjectivo e o quotidiano, assim como as suas modalidades de estudo através do método biográfico; a análise de situações constrói-se em torno das pessoas anónimas, que se transformam em actores e heróis da história. Trata-se de dar a palavra a protagonistas desconhecidos, frente a uma visão excessivamente institucional e desumanizadora do social"

Nas suas palavras encontramos o enquadramento perfeito da experiência que nos propusemos colocar em debate reflexivo, na tentativa de desvendar o "QUEM SOU EU?".

\section{Da escola do Passado à escola do Futuro: A resposta que urge}

Estávamos, já nos finais da década de sessenta do Século passado. Iniciado o nosso trabalho na fase sequencial: Jardim de Infância $\rightarrow$ Escola, onde a actividade lúdica tomava foros de primazia, havia que conhecer a Família, nas suas vivências individuais inerentes a crianças de seis (6) anos, idade cronológica e de idade mental mais ou menos diversa. Assim, não só partíamos do conhecido, das suas vivências reais, como aprofundávamos afectos, íamos conhecendo condicionalismos, reforçávamos as várias fases do AMOR desta célula nuclear: paternal, maternal, filial, bem como as suas implicações extensivas à Família mais alargada.

Neste contexto apareciam actividades multifacetadas incluindo o estudo de palavras simples, mas significativas, como sejam: pai, mãe, menino/menina, avô, avó, neto, neta, tio/tia, através do Método Global de Palavras, experienciado em ANGOLA nos anos de 1968-1975, bem como a sua integração em frases, à medida que íamos avançando.

Ainda no campo do concreto, partimos para o estudo da Escola em todas as suas vertentes: edifício, espaços, contingências, materiais, deveres e direitos como aluno/aluna, professora com implicações educativas recíprocas. Eis que surge, entretanto, a época natalícia com todas as tradições implicativas, seja no âmbito da sua mensagem, seja a nível da formação humana.

Depois disto tudo, onde a ludicidade e o diálogo tinham um cariz permanente, eis que é chegado o momento de saber: -- "Quem sou EU”. A questão custou a ser desvendada. Até que saímos da sala a observar quem passava nos passeios em frente à escola / sala de aulas.

Assim surgiu a palavra Pessoa. Já no nosso local de trabalho, a questão colocava-se se "EU / ALUNO/A, SOU PESSOA".

-- Não. Sou criança; sou menino, sou menina. Até que a professora escreve no quadro, com letra caligráfica, como mandam as boas regras: -- "Eu sou uma pessoa muito importante".

De imediato, surge a confirmação - Pois és. És Professora.

Daqui se desenrolou uma "conversa" demasiado interessante que não cabe em qualquer espaço, por mais simples que se possa pensar: uma verdadeira TESE FILOSÓFICA.

Sob uma orientação cuidada iam surgindo comentários sobre as pessoas que julgavam importantes: o Presidente de ..., o Senhor Padre... o Doutor ... Nem pai, nem mãe. Até que uma criança descobre na palavra "importante" a palavra "porta", já do seu conhecimento, aquando do estudo da "Escola".

-- É verdade! Em coro, surge o reforço da ideia.

E a descoberta seguiu um rumo impensável para qualquer adulto. A Professora só teve que deixar desenrolar o raciocínio e dar a oportunidade de, ordenadamente, cada criança questionar o valor das portas de casa e da sua função. Daí a associação ao valor das duas "PORTAS" que qualquer PESSOA tem, em si mesma: a MENTE e o CORAÇÃO foram momentos de uma intensidade inexplicável. Nas palavras da PSICOPEDAGOGA, apenas iam aflorando questões, oportunamente, dirigidas em função de cada descoberta do sentido de abertura dessas PORTAS como seres pensantes e amantes. Porque, na verdade, TER UMA MENTE QUE PENSA E UM CORAÇÃO QUE AMA encerra toda a razão da nossa existência.

Havia, agora, que passar ao registo escrito que, cada criança, expressou à sua maneira. Surgiram trabalhos excepcionais. Deixamos, apenas, a mensagem de uma delas a representar o produto de tanta sabedoria.

É, tão só, dar-lhes a oportunidade de se expressarem livre e ordeiramente.

Nos dias seguintes o tema prosseguiu num estudo mais pessoal, ainda, relativamente às amizades que havia que construir, em FAMíLIA, em primeiro lugar, na ESCOLA, fazendo dos colegas, amigos e nas relações sociais que começam a despontar incidindo, essencialmente, nas atitudes que havia que tomar, antes de agir e, muitas vezes, depois de agir.

O reforço desta descoberta surgiu, em dias seguintes, num novo texto construído, oralmente, com a colaboração de todas as crianças e que a Psicopedagoga registou, com todo o cuidado, no célebre "QUADRO NEGRO" e que depois de analisado na sua qualidade prática foi objecto de transcrição para o "MEU PRIMEIRO LIVRO” da autoria de cada criança.

O texto rezava assim:

-- Eu sou uma pessoa muito importante. Tenho uma mente que pensa e um coração que ama.

De salientar que no primeiro ano de escolaridade não adoptamos livro editado. Foi sendo construído com o esforço de cada autor, criança, entenda-se, de acordo com normas, previamente, estabelecidas e sob a orientação tutorial da responsável pela formação destas tão "nobres crianças". A Iniciação à leitura / escrita há-de tomar métodos naturais, tal como a criança nos ensina através da aquisição da comunicação oral que, como pais atentos nos dispomos a compreender, a estimular, a apoiar, desde bem cedo.

\section{A (intro)missão dos pais na escola}

Sendo a escola, um espaço de aprendizagem inserido numa sociedade, passa a ser, então, uma COMUNIDADE EDUCATIVA, onde a participação 
dos pais/encarregados de educação, bem como as suas estruturas representativas, são fundamentais.

No período anterior ao 25 de abril de 1974, o movimento associativo de pais, ao contrário de outros movimentos sociais, não tinha qualquer visibilidade social. Essa efeméride trouxe-nos um grande aumento de ASSOCIAÇÕES DE PAIS que passaram a lutar pelo seu direito à intervenção na escola, bem como à mudança de políticas educativas consideradas obsoletas face ao rumo que se impunha, no clima de mudanças e alterações geradoras de inovação e evolução social.

Com o evoluir dos tempos, eis que são criadas as condições propícias ao reconhecimento do direito de associação, passando os pais a ser parte integrante da escola. Uma nova etapa se vislumbra; uma nova oportunidade se abre em exigências de mudança de mentalidades, conformadas em liberdades associativas nascentes.

A oportunidade de intervenção, de (intro) missão, dos pais / encarregados de educação, nas escolas, trouxe-nos vantagens acrescidas a nível de formação individual e colectiva abrangente a todos os órgãos implicados na educação das jovens gerações. Dos Órgãos de Direcção dos estabelecimentos de ensino, faziam, agora, parte os pais a quem se reconheceu o direito de participação na gestão, na orientação, na apresentação de propostas, podendo sugerir, discutir e planear actividades integradoras.

Nas duas últimas décadas, as associações tentaram promover a participação activa dos pais, tendo como objectivo a melhoria das condições de ensinoaprendizagem dos seus filhos/educandos. Foram obtendo respostas efectivas da parte do poder político através da criação de legislação reguladora adequada às novas realidades, da qual deixamos registado o exemplo que se segue: "As associações de pais visam a defesa e a promoção dos interessados e dos seus associados em tudo quanto respeita à educação e ensino dos seus filhos e educandos quer sejam alunos da educação pré-escolar ou dos ensinos básico ou secundário público, particular ou cooperativo" (in artigo $2^{\circ}$ do Decreto-Lei $n^{\circ} 372 / 90$, de 27 de novembro, com alterações do Decreto-Lei $n^{\circ} 80 / 99$ de 16 de março e lei $n^{\circ}$ 29/2006 de 4 de julho).

Iam surgindo, assim, escolas com mais e melhores condições de trabalho e de vida, cantinas escolares, escola a tempo inteiro. São alguns dos exemplos que se foram tornando a realidade bem diferente dos tempos anteriores.

De Decreto-Lei, em Decreto-Lei, constituiu-se, assim, por via legal o reconhecimento efectivo da participação dos pais na escola. Porém, isso não se constituiu a condição suficiente para que essa participação encontre o eco desejado, indispensável a uma organização educativa assumida e partilhada.

Ainda que confiantes no futuro, temos que reconhecer que tal legislação contempla um conjunto de princípios que, na prática, não conduzem a uma real participação. Essa participação é condicionada, pois não foram criadas condições de participação em igualdade de circunstâncias com outros intervenientes e isso tem vindo a reflectir-se nas limitações que se fazem sentir ao nível das políticas e orientações governamentais. Apresentamos como exemplo a reorganização da rede escolar, a criação dos megaagrupamentos, o elevado número de alunos por turma, uma burocracia desmesurada, entre outras, ainda que, de menor relevo.

Os novos modelos familiares procedentes das transformações sociais vigentes influenciam e causam mudanças nas relações familiares. Com a emancipação da mulher e a actual divisão de tarefas familiares, surge um novo conceito de família. Os progenitores têm uma dupla actividade, dentro e fora de casa. A estrutura familiar tem de ser ajustada a tais condições. A partilha de tarefas domésticas toma, assim, uma necessidade urgente de alteração de hábitos adquiridos, fruto de uma educação de séculos. A emancipação da mulher toma foros de implicações diferenciadas. Hoje, marido e esposa, têm que assumir-se como seres complementares aos mais altos níveis das estruturas domésticas, comunitários, profissionais, sociais.

A inserção do complemento familiar em prol de uma escola que se quer renovada prevê e exige que marido e esposa se assumam como verdadeiros encarregados de educação dos seus filhos, em associações devidamente legalizadas. A sua participação nos Órgãos de Gestão respectivos foi uma conquista das últimas décadas do século XX, que, aliás, saudamos ainda que com todas as vicissitudes.

\section{$O$ reverso da medalha: abertura da escola à comunidade}

Segundo Perrenoud e Montadon (2001), a relação entre a escola e a família pode estar condicionada pela "diversidade de concepções relativas à socialização, ao bem da criança e à legitimidade desta ou daquela prática educativa. Nem a escola está preparada para abrir as suas portas aos pais, nem uma grande parte dos pais está preparada para intervir na escola (...)”. Isto gera, frequentemente, situações de tensão e conflitos entre ambas as instituições que têm que ser superadas e ultrapassadas para geração do bem estar funcional a que todos temos direito.

A missão da família e da escola, funda-se na compreensão de que uma necessita da outra, e que se uma destas instituições não cumprir o seu papel, a outra fica completamente comprometida, acabando por dificultar o desenvolvimento da pessoa que cada qual representa.

Tem que haver uma relação de confiança entre pais, professores educativos sendo indispensável criar redes de comunicação extensivas a um trabalho conjunto das partes envolvidas, para que a comunicação se estabeleça de maneira eficaz.

Para compreendermos melhor a relação entre a escola e a família, aconselhamos uma leitura atenta sobre a tipologia de envolvimento parental de Joyce Epstein (1992). Este autor alerta-nos, de forma categórica, para as condições sócio-culturais de muitas famílias que são, por vezes, causadoras de aproximação ou distanciamento de culturas dominantes.

Como Educadores conscientes das nossas responsabilidades, actuar de forma compreensiva, 
perante tais situações, pode aliviar o grau de tensão gerada entre elementos de grupos de pais mais conflituosos devido ao status de origem dos próprios, sendo também estes geradores de distanciamentos e consequentes tensões.

Muitos dos estudiosos deste século, ainda muito no seu início, têm alertado para esse tipo de relações geradoras de mal estar. A título de exemplo citamos Pedro Silva (2003), que considera que entre pais e professores se tem construído uma relação "onde se joga essencialmente à defesa."

Em Don Davies (1989), encontrámos uma visão mais optimista ao afirmar que a participação dos pais contribui para estreitar as relações entre a escola e a família, para elevar a autoestima, para incrementar a influência, o fortalecimento de redes sociais e para um maior reconhecimento e valorização social por parte de uma sociedade que tem que assumir-se como construtora de ideais. Segundo este autor, todos ganham com esta cultura da participação, seja através do diálogo estabelecido, seja pela partilha de responsabilidades, seja, ainda, pelo respeito que cada ser humano nos merece.

Há que criar uma nova visão relacional, pela positiva, até porque, quer queiramos quer não, o certo é que a família e a escola são duas instituições que, obrigatoriamente, se cruzam, se interligam, se regem em função das exigências de uma sociedade mais livre.

Essas transformações sociais alteram as actuais relações familiares que, por sua vez, também irão transformar-se influenciando as futuras gerações. Estas transformações ocorrem através de um processo de influências entre os membros da família e os diferentes ambientes presentes na sociedade em que vivem. $\mathrm{O}$ ambiente escolar é um dos principais influenciadores e a instituição familiar acaba por ir absorvendo essa influência.

É nesse contexto que o individuo se constrói e molda a sua personalidade.

A oportunidade e actualidade desta noção é sustentada por Swap (citado por Pereira, 2008: 38), ao considerar ser necessário que os pais e os professores se ajudem mutuamente, num contexto em que vale a pena apostar.

Por um lado, os professores vivem as dificuldades acrescidas pela institucionalização do ensino obrigatório que resultou no ensino de massas. Por outro lado, o pouco reconhecimento do seu estatuto profissional tem afectado, gravemente, a sua condição de agentes educativos, conscientes das responsabilidades assumidas.

Reconhecidos por um estatuto sócio-profissional dignificante, seja pelas famílias, seja pelas comunidades que serviram, durante séculos, vêem-se, hoje, completamente desmotivados, pela desvirtualização do seu trabalho de índole pedagógicodidáctica.

Esteve (1992:120), é peremptório ao afirmar que “ $a$ chave do mal-estar docente mestá na desvalorização do trabalho do professor, evidente no nosso contexto soicial e nas deficientes condições de trabalho do professor na sala de aula, que o obrigam a uma actuação medíocr, pela qual acaba sempre por ser considerado responsável".

Também a burocracia invadiu as próprias salas de aulas e, gerir todos esses campos, não é tarefa fácil. Por outro lado, a sua vida pessoal e familiar sofreu, também, agressões de difícil gestão, originando toda uma complexidade vital de difícil gestão. A resistência aos embates causados por situações de divórcio, de desemprego, de mentalidades rotinizadas o que vem afectar problemáticas vividas em família com a reflexão correspondente na escola.

O sistema escolar apodera-se, assim, do território familiar e a escola interessa-se cada vez menos com o desenvolvimento dos alunos em domínios que tenham a ver com a globalidade do ser. Consequentemente, a margem de intervenção familiar, na escola, é cada vez menor. Estamos a falar, por exemplo, das escolhas no domínio da actividade profissional, uma vez que os projectos profissionais que os pais alimentam para os seus filhos são frequentemente contrariados pela escolaridade formal: Diogo (1998: 51).

A função estatutária, atribuída à família, na sociedade dos nossos dias, não é, facilmente, gerível, já que lhe é exigida uma responsabilidade para a qual, segundo Nunes, (citado por Pereira, 2008:39), as famílias não se encontram devidamente preparadas para o exercer esse papel.

\section{A escola - um espaço de boas práticas}

"Razão e paixão no discurso utópico sobre educação”, Monteovila (2002: 287-306). Eis a mensagem que tomámos como motor fundamental das nossas práticas educativas.

“ (...) na realidade, se nos situarmos no verdadeiro sentido do termo, esta maneira de ser escola não passa de isso mesmo: utopia, sonho, quimera, fantasia, imaginação, criatividade, loucura, tentando fugir ao ramerrame de um trabalho rotineiro em que muito boa gente se deixou embrenhar" (Gomes de Sousa, 2011:19).

Muitos são os caminhos que nos conduzem a esse espaço que consideramos repleto das mais profundas sensações gratificantes. Ao longo dos vários anos que percorremos, a nossa conduta pautou-se, sempre, pela criação de um ambiente relacional de qualidade, um ambiente humano sustentado na alegria, na empatia, no bem receber, na abertura à diversidade de pontos de vista, no diálogo respeitador entre o TU e o EU, na aceitação de pontos de vista diferentes, na troca de ideias, de pensamentos, de saberes, uma verdadeira utopia, nos tempos que correm.

Neste espaço, apenas nos propomos deixar algo com que nos identificamos e reforçar a aposta na construção de uma escola pela positiva. Assim sendo gostaríamos de voltar a percorrer as páginas de um "programa de capas amarelas" guardado com todo carinho. Nele se encontram pistas riquíssimas de possibilidades de "aprender brincando/jogando", com os números e as palavras, com paus e pedras, material multibásico e de Cuisenaire, o que proporciona um entrosamento interdisciplinar, transdisciplinar, multidisciplinar, 
facilitador da aquisição dos conteúdos científicos, por mais complexos que nos possam parecer, à priori.

O recurso às denominadas "Áreas de Expressão": teatro, educação física, dança, música, manualidades diversas, (...), desenho, "ab"usado na ilustração dos trabalhos e não só, são momentos de uma riqueza de aprendizagens múltiplas numa adesão total. Aí se descarregam as emoções mais fortes e se estimula a força motivadora para o estudo das áreas de cariz mais científico

São práticas onde o lúdico toma foros de entusiasmo, alegria e aprendizagem de tudo quanto o professor é o dinamizador primeiro. Através dessa forma de fazer escola, cada criança, adolescente, jovem, adulto, floresce em toda a sua fragrância, com toda a pujança pessoal que o/a caracteriza.

A motivação é a mola real que se abre de múltiplas formas. O professor tem, neste contexto, um papel de líder e, toda a gente sabe que uma boa liderança conduz a boas práticas.

Cabe-nos uma referência muito especial à área da música. A sua importância, na escola torna-se numa arte indiscutível. Possibilita o trabalho das emoções, o desenvolvimento da sensibilidade, a percepção auditiva, a sociabilidade, em todas as fases etárias, em todas as condições sociais. Destaca-se, ainda, a oportunidade de ampliação da bagagem cultural com a aprendizagem de canções musicadas, nas mais variadas línguas e, no que se refere à Língua Portuguesa, a sua mensagem penetra profundamente.

Reboredo (2003:15-16), afirma que “ (...) a música não é inútil nem supérflua, nem destinada apenas a uma categoria de pessoas dotadas ou ricas (...)”. Mais adiante acrescenta, ainda, que " (...) a música é encarada como um contributo para a formação geral da personalidade da criança."

Segundo Oliveira (1996:27), na antiguidade, filósofos gregos consideravam a música como “(...) uma dádiva divina para o homem (...)".

Só isto nos bastaria para fazer das nossas aulas um local e um momento de musicalidade especial e específica. Todo o ensino da música deve ser acompanhado de percepção musical, apreciação musical, prática de conjunto e uma série de outras matérias que são complementares. Vários autores concordam que a articulação se carateriza pela intensidade das trocas entre os especialistas e pelo grau de integração real das disciplinas, no interior de um projeto específico de pesquisa.

A interpretação de canções, por exemplo, assim como qualquer manifestação musical, pode provocar um desejo de busca natural de vários tipos de conhecimentos artísticos. Pois, a partir da experiência musical vivenciada, os componentes do coro podem interessar-se pela literatura, pelas artes plásticas e até mesmo por outras ciências e técnicas, como refere Snyders (1992).

A música contribui fortemente para a melhoria da disciplina interior e exterior das nossas crianças e adolescentes.

\section{Trabalho de intervenção}

O presente estudo apresenta os resultados e análise dos dados recolhidos através de um inquérito, por questionário, realizado junto dos alunos, pais e encarregados de educação e professores de um Agrupamento de Escolas do Distrito de Vila Real, concelho de Chaves.

Através desta recolha de informação procura-se contribuir para a avaliação do funcionamento do Agrupamento e da sua capacidade para alcançar as metas a que se propõe e ainda para apoiar processos de tomada de decisão que conduzam ao desenvolvimento da instituição educativa.

O estudo está estruturado em cinco partes, sendo a primeira constituída por uma breve revisão bibliográfica, na qual se identifica e contextualiza o estudo realizado. $\mathrm{Na}$ segunda parte, explicita-se a metodologia utilizada no processo e, na terceira parte, designada de "Resultados", faz-se uma breve caracterização dos diferentes participantes e apresentam-se os resultados obtidos. Na quarta parte, reúne-se a informação recolhida, numa perspectiva qualitativa, evidenciando os "Pontos Fortes" e os "Aspectos a Melhorar".

\section{Metodologia}

No inquérito foram utilizados os modelos de questionário aplicados nos anos lectivos anteriores depois de submetidos a alterações pontuais que se julgaram pertinentes, de modo a permitir uma análise comparativa e aferir conclusões sobre o nível de desempenho da instituição e evidenciar domínios que necessitam de ser melhorados.

Os modelos de questionários lançados no Agrupamento de Escolas, resultaram da adaptação de questionários recolhidos em fontes diversas, referidas nas referências bibliográficas.

Os questionários foram aplicados ao universo do pessoal docente; aos alunos e aos pais/encarregados de educação foram aplicados através de uma amostra representativa, cuja selecção foi realizada, aleatoriamente.

Ao pessoal docente a inquirição foi feita através de uma plataforma de questionários on-line; aos alunos e aos pais/encarregados de educação foram distribuídos questionários em formato papel.

\section{Resultados}

\section{Alunos}

Os 213 alunos que participaram distribuem-se pelos seguintes níveis de ensino:

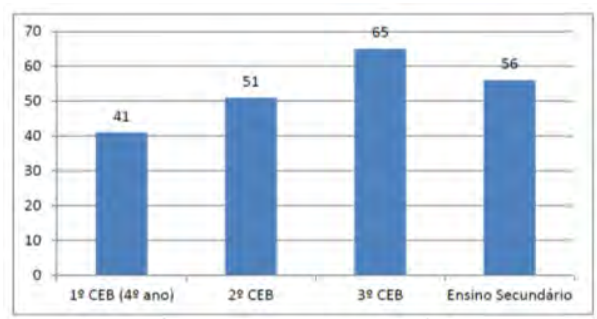




\section{Alunos do $1^{\circ}$ CEB}

\section{A -- Caracterização}

Os 41 alunos do $4^{\circ}$ ano que participaram têm idades compreendidas entre os 9 e os 11 anos $(M=9,7$; $\mathrm{DV}=0,50)$. Em relação ao sexo dos participantes, 21 $(51,2 \%)$ pertencem ao sexo masculino e $20(41,8 \%)$ pertencem ao sexo feminino.

\section{B - Nível de satisfação}

Relativamente aos resultados dos questionários aplicados aos alunos do $4^{\circ}$ ano sobre o seu grau de satisfação no que respeita ao funcionamento da escola e dos serviços prestados obteve-se uma média de 4,20 média adaptada à escola da CAF.

\section{Alunos do $2^{\circ}$ CEB}

\section{A - participação e caracterização}

Participaram 51 alunos do $2^{\circ} \mathrm{CEB}$, dos quais 16 $(31,4 \%)$ frequentam o $5^{\circ}$ ano e $35(68,6 \%)$ frequentam o $6^{\circ}$ ano, com idades compreendidas entre os 10 e os 13 anos $(M=11,4 ; \mathrm{DP}=0,76)$. Em relação ao sexo dos participantes $31(62 \%)$ pertencem ao sexo feminino e 19 (38\%) pertencem ao sexo masculino.

\section{B - nível de satisfação}

Relativamente aos resultados dos questionários aplicados aos alunos do $2^{\circ}$ ciclo sobre o seu grau de satisfação no que respeita ao funcionamento da escola e dos serviços prestados obteve-se uma média de 4,26 média adaptada à escola da CAF.

\section{Alunos do $3^{\circ} \mathrm{CEB}$}

\section{A - Participação e caracterização}

Participaram 65 alunos do $3^{\circ} \mathrm{CEB}$, com idades compreendidas entre os 12 e os 16 anos $(\mathrm{M}=13,7$ $\mathrm{DP}=1,04)$. Em relação ao sexo dos participantes 35 $(62,5 \%)$ pertencem ao sexo feminino e $25(44,6 \%)$ pertencem ao sexo masculino.

\section{$B$ - Nível de satisfação dos alunos do $3^{\circ}$ CEB}

Relativamente aos resultados dos questionários aplicados aos alunos do $3^{\circ} \mathrm{CEB}$ sobre o seu grau de satisfação no que respeita ao funcionamento da escola e dos serviços prestados obteve-se uma média de 3,93 média adaptada à escola da CAF

\section{Alunos do ensino secundário}

\section{A - Participação e caracterização}

Participaram 56 alunos do ensino secundário, com idades compreendidas entre os 15 e os 20 anos $(\mathrm{M}=16,7 \quad \mathrm{DP}=1,35)$. Em relação ao sexo dos participantes $31(59,6 \%)$ pertencem ao sexo feminino e $21(40,4 \%)$ pertencem ao sexo masculino.

\section{B- Nível de satisfação dos alunos do ensino secundário}

Há que salientar que, relativamente aos resultados dos questionários aplicados aos alunos do ensino secundário sobre o seu grau de satisfação no que respeita ao funcionamento da escola e dos serviços prestados obteve-se uma média de 3.69 - média adaptada à escola da CAF.

Da análise do gráfico 2 conclui-se que existe um elevado nível de satisfação dos alunos do Agrupamento, no que respeita ao funcionamento e serviços prestados. Verifica-se um padrão de satisfação similar ao do ano letivo anterior, mas salienta-se que o nível de satisfação diminuiu em todos os níveis de ensino, à exceção do $1^{\circ}$ ciclo, que aumentou; continua a registar-se diferença no nível da satisfação dos alunos da escola sede comparativamente com os restantes estabelecimentos de ensino.

O gráfico seguinte resume os níveis de satisfação dos alunos, por ciclo/nível de ensino:

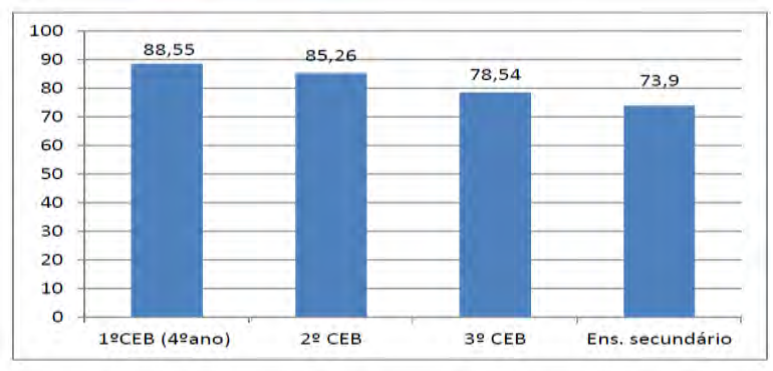

\section{Pais/Encarregados de Educação}

\section{A -- Participação}

Os 230 Encarregados de Educação que participaram distribuem-se pelos seguintes níveis de ensino:

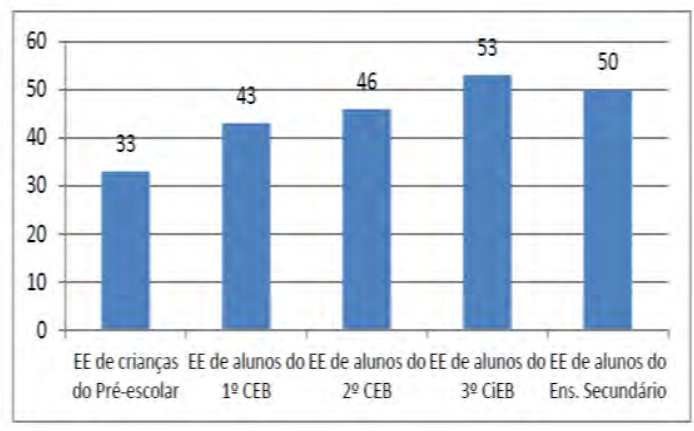

\section{Pais/Enc. Educação - Pré-escolar}

\section{A -- Caracterização}

Os 33 encarregados de educação participantes têm idades compreendidas entre os $\leq 30$ e os 50 anos. Em relação ao sexo, identificaram-se 26 (100\%) respondentes do sexo feminino. Em relação às habilitações literárias, 1 possui o $1^{\circ} \mathrm{CEB}(3 \%), 2$ o $3^{\circ}$ CEB ( $6,1 \%), 8$ o ensino secundário $(24,2 \%)$ e 17 possuem Licenciatura $(51,5 \%)$ e 5 possuem Mestrado ( $15,2 \%)$.

\section{B - Nível de satisfação}

Relativamente aos resultados dos questionários aplicados aos pais/encarregados de educação das crianças do Pré-escolar sobre o seu grau de satisfação 
no que respeita ao funcionamento do Jardim de Infância e dos serviços prestados obteve-se uma média de 4,61 - média adaptada à escola da CAF.

\section{Pais/Enc. Educação -1º CEB}

\section{A -- Caracterização}

Os 43 encarregados de educação participantes têm idades compreendidas entre os $\leq 30$ e os 50 anos. Em relação ao sexo, $7(17,1 \%)$ pertencem ao sexo masculino e 34 (82,9\%) pertencem ao sexo feminino. Em relação às habilitações literárias dos encarregados de educação, 3 possuem o $2^{\circ} \mathrm{CEB}$ (7\%), 11 o ensino secundário (26,6\%), 3 possuem Bacharelato (7\%), 23 possuem Licenciatura (53,5\%) e 3 (7\%) Mestrado.

\section{B -- Nível de satisfação}

Relativamente aos resultados dos questionários aplicados aos pais/encarregados de educação dos alunos do $1^{\circ}$ Ciclo sobre o seu grau de satisfação no que respeita ao funcionamento da escola e dos serviços prestados obteve-se uma média de 4,34 - média adaptada à escola da CAF.

\section{Pais/Enc. Educação -2 CEB}

\section{A - Caracterização}

Os 46 encarregados de educação que participaram têm idades compreendidas entre $\geq 30$ e os 55 anos. Em relação ao sexo, 5 (12,5\%) pertencem ao sexo masculino e 35 (87,5\%) pertencem ao sexo feminino. Em relação às habilitações literárias dos encarregados de educação 103 possuem o $2^{\circ} \mathrm{CEB}(6,5 \%), 9$ o $3^{\circ}$ CEB (19,6\%), 18 o ensino secundário (39,1\%), 1 possui bacharelato $(2,2 \%), 12$ possuem licenciatura $(26,1 \%)$ e $3(6,5 \%)$ mestrado.

\section{B -- Nível de satisfação}

Relativamente aos resultados dos questionários aplicados aos pais/encarregados de educação dos alunos do $2^{\circ}$ ciclo sobre o seu grau de satisfação no que respeita ao funcionamento da escola e dos serviços prestados obteve-se a média de 3,96 - média adaptada à escola da CAF.

\section{Pais/Enc. Educação - $3^{\circ}$ CEB}

\section{B -- Caracterização}

Os 42 encarregados de educação que participaram têm idades compreendidas entre $\leq 30$ e os 55 anos. Em relação ao sexo, 6 (13\%) pertencem ao sexo masculino e $40(87 \%)$ pertencem ao sexo feminino. Em relação às habilitações literárias dos encarregados de educação, 4 possuem o $1^{\circ}$ ciclo $(7,5 \%), 7$ o $2^{\circ} \mathrm{CEB}(13,2 \%), 12$ o $3^{\circ}$ CEB (22,6\%), 18 o ensino secundário (34\%) e 2 possuem Bacharelato (3,8\%), 9 possuem Licenciatura (17\%), e 1 (1,9\%) Mestrado.

\section{C -- Nível de satisfação}

Relativamente aos resultados dos questionários aplicados aos pais/encarregados de educação dos alunos do $3^{\circ}$ ciclo sobre o seu grau de satisfação no que respeita ao funcionamento da escola e dos serviços prestados obteve-se a média de 3,97- média adaptada à escola da CAF.

\section{Pais/Enc. Educação -Ensino Secundário}

\section{A -- Caracterização}

Os 50 encarregados de educação que participaram têm idades compreendidas entre os $\leq 30$ e os 55 anos. Em relação ao sexo, 9 (20,5\%) pertencem ao sexo masculino e $35(79,5 \%)$ pertencem ao sexo feminino. Em relação às habilitações literárias dos encarregados de educação, 2 possui o $1^{\circ}$ ciclo $(4 \%), 5$ o $2^{\circ} \mathrm{CEB}$ (10\%), 7 o $3^{\circ} \mathrm{CEB}(14 \%), 18$ o ensino secundário $(36 \%), 2$ possuem Bacharelato (4\%), 13 possuem Licenciatura (26\%), 1 possui Mestrado (2\%) e 1 Doutoramento (2\%).

\section{C -- Nível de satisfação}

Relativamente aos resultados dos questionários aplicados aos pais/encarregados de educação dos alunos do ensino secundário sobre o seu grau de satisfação no que respeita ao funcionamento da escola e dos serviços prestados obteve-se a média de 3,84 média adaptada à escola da $\mathrm{CAF}$.

O gráfico seguinte resume os níveis de satisfação dos pais/ encarregados de educação, por ciclo/nível de ensino:

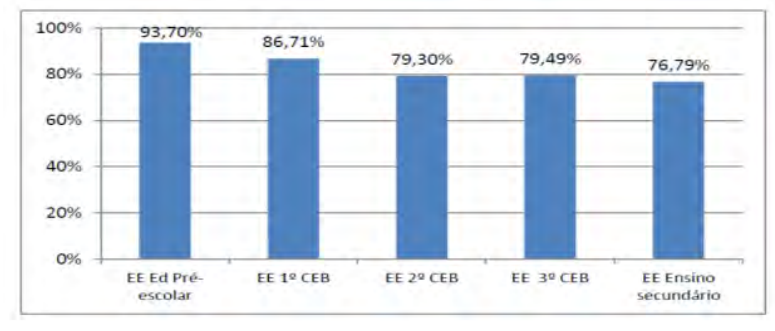

Da análise do último gráfico conclui-se que existe um elevado nível de satisfação dos encarregados de educação do Agrupamento, no que respeita ao funcionamento e serviços prestados. Verificou-se, contudo, uma diminuição dos níveis de satisfação em todos os setores à exceção do referente a EE da Ed. Pré-escolar, que aumentou, e do referente a EE do ensino secundário, que se mantém praticamente igual. O padrão de satisfação é muito similar ao obtido no ano letivo anterior, verificando-se, globalmente, uma diminuição progressiva com o aumento do nível de ensino dos educandos. 


\section{Pessoal Docente}

\section{A -- Participação}

Participaram 131 docentes, assim distribuídos pelos diferentes departamentos curriculares:

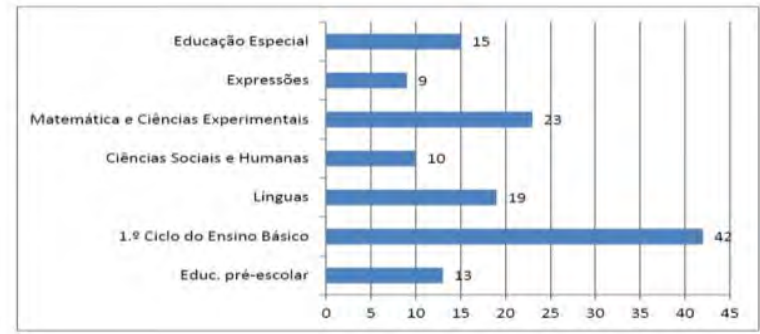

Número de docentes participantes por nível de ensino leccionado:

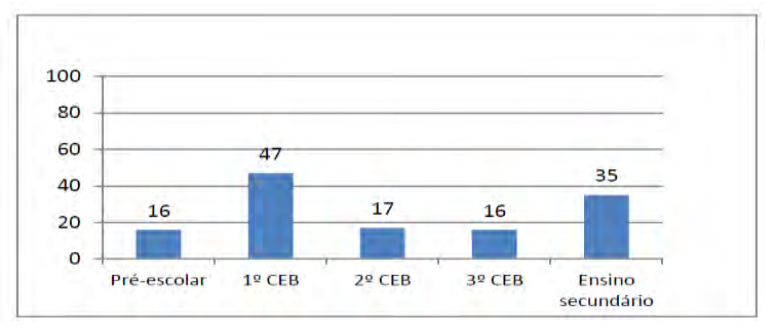

\section{B -- Caracterização}

Os docentes participantes têm idades compreendidas entre os 30 e $\geq 55$ anos (gráfico 11). Em relação ao sexo, $17(13 \%)$ pertencem ao sexo masculino e 114 $(87 \%)$ pertencem ao sexo feminino.

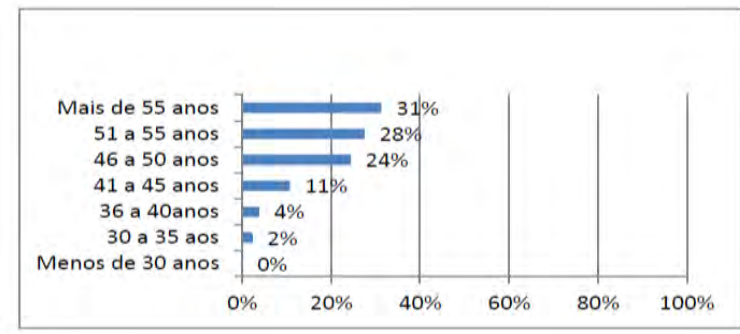

Em relação às habilitações literárias, 5 possuem Bacharelato $(3,8 \%), \quad 100$ e possuem Licenciatura (76,3\%) e 26 possuem Mestrado (19,8\%) .

\section{C -- Nível de satisfação}

O gráfico seguinte resume o nível de satisfação do Pessoal Docente por nível de ensino:

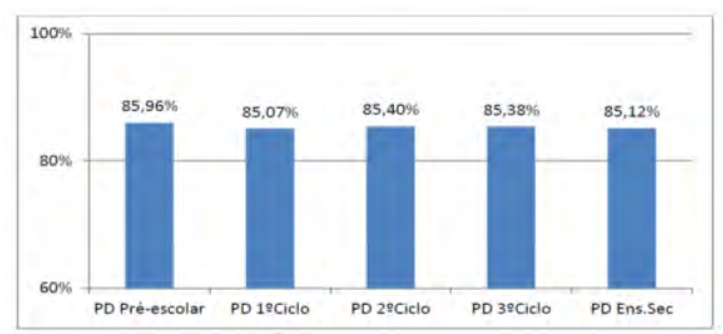

A análise do gráfico anterior evidencia um elevado nível de satisfação do pessoal docente. Contudo, comparando estes resultados com os obtidos no ano letivo anterior, verifica-se que ocorreu uma diminuição nos níveis de satisfação, em todos os níveis de ensino. Acentuou-se a tendência a uma maior aproximação dos valores obtidos, os quais oscilam agora entre os $85,07 \%$ e os $85,96 \%$.

\section{Pontos fortes e aspectos a melhorar}

Apresentam-se de seguida os resultados numa perspetiva qualitativa, evidenciando os "Pontos Fortes" e os "Aspetos a Melhorar" no âmbito dos diferentes critérios e subcritérios do Modelo CAF- Educação. Consideram-se como "Pontos Fortes" os que se referem aos aspetos que o Agrupamento já desempenha com qualidade e sobre os quais a satisfação da comunidade educativa é bastante positiva; por outro lado, os "Aspetos a Melhorar" são os aspetos em que o Agrupamento ainda não conseguiu alcançar o nível necessário à obtenção de uma maior satisfação por parte dessa mesma comunidade.

A pontuação de referência dos pontos fortes e a pontuação de referência dos aspetos a melhorar foi calculada a partir do valor da média final cada sector (alunos, EE e PD): para a identificação dos pontos fortes somou-se o valor do desvio padrão à média final e para a identificação dos aspetos a melhorar, subtraiuse o valor do desvio padrão à média final.

\section{Considerações finais}

A aplicação do inquérito e a análise dos resultados permitiu obter dados que devem contribuir para incentivar ações e processos de melhoria da qualidade, do funcionamento e dos resultados deste Agrupamento.

Neste sentido, face aos resultados obtidos a equipa entende que devem ser salientados os seguintes aspetos:

a) - A diminuição global verificada nos níveis de satisfação dos diferentes atores inquiridos, alunos, pais e encarregados de educação e pessoal docente, tomando como referência o inquérito aplicado no ano letivo anterior;

b) - A unanimidade que se verifica, no seio de cada grupo/nível de ensino inquirido, na identificação do que se refere a aspetos que o Agrupamento já desempenha com qualidade - e sobre os quais a satisfação é bastante positiva.

c) - A unanimidade que se verifica, no seio de cada grupo/nível de ensino inquirido, na identificação de aspetos em que o Agrupamento ainda não conseguiu alcançar o nível necessário à obtenção de uma desejada satisfação.

d) - A coincidência que se verifica, entre a totalidade de aspetos que são objeto de menor satisfação por parte dos alunos do $3^{\circ} \mathrm{CEB}$ e dos alunos do Ens. Secundário.

Assim, os pontos que foram considerados como Fortes devem ser objeto de acompanhamento, de modo a reforçar a vantagem competitiva e de sustentabilidade 
dos esforços já realizados e os aspetos identificados como a Melhorar deverão conduzir ao aperfeiçoamento da definição, hierarquização e priorização das ações, de acordo com a capacidade do Agrupamento para as implementar, tendo sempre em conta o impacto com que cada ação poderá contribuir para a melhoria da satisfação da comunidade escolar e a melhoria no desempenho da instituição.

\section{Conclusão final do trabalho}

Muitas são as ideias que foram ficando registadas neste trabalho, organizado e realizado em em grupo, parceria criada com base nesses laços afectivos gerados e geridos em tempos que já lá vão, mas que, nem por isso nos afastou em ideais comuns que continuamos a partilhar e a receber. $\mathrm{O}$ mesmo não aconteceu com os locais de trabalho, as escolas edificadas neste Portugal Interior disperso.

Porém, há que assinalar que nem por isso essas relações se esfriaram. Bem pelo contrário. Fortaleceram-se no reencontro benfazejo que, hoje, nos une em Associação que, ainda que numa infância de poucos anos de idade mais ou menos estável, vamos levando a um crescimento, nem sempre rectilíneo, como é natural, tal como se pode constatar em depoimentos anteriormente analisados. Denominada como "Casa do Professor de Chaves, Alto Tâmega e Barroso" tem como intenção elevar a consideração e a estima dos seus associados, bem como a abertura à comunidade através de projectos intergeracionais de ocupação de tempos livres.

Todas as nossas propostas de funcionamento têm como sentido único reverter e converter todas as falhas relacionais humanas assinaladas no decurso deste trabalho em momentos de convívio salutar e a ocupação de tempos livres de forma produtiva, socialmente falando.

Em nossa convicção, retirada de uma prática consciente, de longos anos, as relações escola - família - comunidade, não se constroem por Decretos-Lei emanados de gabinetes por quem desconhece as realidades escolares deste Portugal interior que muito amamos. Faz-se de humildade, de acolhimento, de aceitação, de reconhecimento pelo fruto de um trabalho realizado com abnegado amor à causa que defendemos.

De salientar que esta conclusão ultrapassa a primeira ideia que pode vir à mente: acabou.

Não, muito pelo contrário. $\mathrm{O}$ trabalho prossegue o seu ritmo normal de acordo com a disponibilidade de que dispomos do feed-back que recebemos e dos objectivos que definimos.

Venham ter connosco e encontrarão, decerto, o acolhimento pessoal / grupal desejado.

\section{Referências bibliográficas}

Alaíz, V., Góis, E., \& Gonçalves, C. (2003). AutoAvaliação de Escolas: Pensar e Praticar. Lisboa: Edições ASA.

Alarcão, M. (2000) (des)Equilibrios Familiares. Coimbra: Quarteto.

Davies, Don, E. A. (1989). As escolas e as Famílias em Portugal: Realidade Perspetivas. Lisboa: Livros Horizonte.

Diogo, José, Parceria (1998). Escola - Família. A caminho de uma escola participada. Porto: Porto Editora.

Esteve, J. M. (1991). Mal estar docente. Porto: Porto Editora.

Gomes De Sousa, I. D. (2011). Escola De Ontem E De Hoje: UM PUNHADO DE RECORDAÇÕES. Montalegre: Seara Gráfica.

Leandro, E. (2002). Guião para autoavaliação de desempenho. Instituto Nacional de Administração.

Montadon, Cléopatre E Perrenoud, Philipe (2001). Entre pais e professores, um diálogo impossivel Para um Análise Sociológica das Interações Entre a Familia e a Escola. Oeiras: Celta Editora.

Monteovila, M. V. (2002). Razión y pasión en el discurso utópico sobre educación. En Escolano nenito \& J. M. Hernández Díaz (Eds), La memoria y el deseo : Cultura de la Escuela y educación deseada. (pp. 287-306). Valencia Tirant lo Blanch.

Oliveira, R. (1996). Música, saúde e magia. Teoria e prática na Música Orgânica. Rio de Janeiro: Nova Era.

Reboredo, J. M. L. (2003). Um Cancioneiro em Estudo. Gailivro.

Silva, P. (2003). Escola- Família, Uma Relação Armadilhada - Interculturalidade e Relações de Poder. Porto: Afrontamento.

Snyders, G. (1992).A Escola Pode Ensinar As alegrias da música. São Paulo: $2^{\mathrm{a}} \mathrm{ed}$. Cortez.

Strecht Ribeiro, T. De J. R. L. (2003). Relação EscolaFamília - Uma Comunicação Essencial. Porto: Escola Superior de Educação de Paula Frassinetti, Complemento de Formação em Comunicação Educacional e Gestão da Informação.

Suarez Pazos, M. (2002). Histórias de Vida y fonte oral. Los Recuerdos escolares. En A. Escolano Benito \& J. M. Hernández Diaz (eds). La memória e el deseo: Cultura de la escuela y educación deseada. (pp. 107-133). Valencia: Tirant lo Blanch.

Tedesco, J. M. (1975). El Nuevo Pacto Educativo: EDUCACIÓN, COMPETITIVIDAD Y CIUDADANÍA EN LA SOCIEDAD MODERNA. ALAUDA: ANAYA. 